\title{
Kurloff Cells Measurement
}

National Cancer Institute

\section{Source}

National Cancer Institute. Kurloff Cells Measurement. NCI Thesaurus. Code C96682.

The determination of the amount of large secretory granule-containing immune cells in a biological specimen taken from members of certain genera of the Caviidae family. 